\title{
Role of Endogenous Secretin in Acid-induced Inhibition of Human Gastric Function
}

\author{
J. H. Kleibeuker, V. E. Eysselein, V. E. Maxwell, \\ and J. H. Waish \\ Center for Ulcer Research and Education, \\ Veterans Administration Wadsworth Hospital Center, \\ Los Angeles California 90073; University of California, \\ Los Angeles, California 90024
}

bstract. The role of secretin in the inhibition of gastric acid secretion that occurs during acidification of the gastric lumen was studied in nine healthy men. Gastric acid secretion was stimulated by $500-\mathrm{ml}$ meals of $8 \%$ peptone solution, and the $\mathrm{pH}$ of the stomach was maintained at $5.5,2.5$, or 2.0 by intragastric titration. The increase in plasma secretin was measured, after extraction, by a new secretin radioimmunoassay. After determining the intravenous dose of secretin required to reproduce plasma secretin concentrations achieved during pH 2.5 and 2.0 meals, similar doses were given during administration of a $\mathrm{pH} 5.5$ peptone meal. The doses of secretin led to plasma secretin concentrations that averaged $3.4 \mathrm{pM}$, not different from the 3.2 and $3.9 \mathrm{pM}$ concentrations achieved during acidified meals. However, exogenous secretin infusion failed to inhibit acid secretion or gastrin response to peptone, although significant inhibitions occurred in both during peptone meals given at $\mathrm{pH} 2.5$ or 2.0 . When secretin infusions were given at fivefold higher rates, plasma gastrin responses again failed to demonstrate significant inhibition. Gastric emptying was inhibited significantly by both acidified peptone meals but only slightly $(P=0.053)$ during exogenous infusion of physiologic secretin doses. The decrease in acid secretion could be explained by decreased gastrin release, but neither of these findings could be explained by circulating secretin concentrations. These results cast strong doubt on a physiological role of secretin in inhibition of acid secretion in man.

Address reprint request to Dr. John H. Walsh, Veterans Administration Wadsworth/CURE, Veterans Administration Wadsworth Hospital Center, Bldg. 115, Room 217, Los Angeles, CA 90073.

Received for publication 23 August 1983 and in revised form 24 October 1983.

The Journal of Clinical Investigation, Inc.

Volume 73, February 1984, 526-532

\section{Introduction}

Secretin is released by endocrine cells in the mucosa of the duodenum and upper jejunum when the intraduodenal $\mathrm{pH}$ falls below 3 to $4(1-3)$. The amount of secretin released probably is dependent on the total amount of titratable acid delivered to the duodenum. It is now generally accepted that secretin is a physiologic stimulant of pancreatic water and bicarbonate secretion $(4,5)$. Whether it has any other function has not yet been established. Exogenous secretin in supraphysiologic doses inhibits acid secretion and gastrin release, basally as well as in response to a variety of stimuli (6-10).

Recent studies in the $\operatorname{dog}(11,12)$ indicate that secretin is a physiologic inhibitor of gastric acid secretion and gastrin release. So far, this has not been reported in man. A recent study (13) showed that secretin in low doses inhibits the gastric emptying of liquid meals in humans. We have found that inhibition of peptone-stimulated acid secretion at low intragastric $\mathrm{pH}$ was due entirely to inhibition of gastrin release (14).

We used a newly developed radioimmunoassay for secretin to study whether circulating secretin is a mediator of this acidinduced inhibition of gastrin release and acid secretion. In addition, we studied the gastric emptying rate.

\section{Methods}

Nine healthy male subjects (mean age $38 \mathrm{yr}$, range 20-69 yr) without previous gastric or duodenal disorders were studied. All gave written informed consent. The study was approved by the Human Studies Committee at Veterans Administration Wadsworth Center. After an overnight fast a nasogastric tube (AN 10, Andersen Samplers Inc., Atlanta GA) was passed into the stomach. The position of the tube was checked by a water-recovery (15) test and, if necessary, by fluoroscopy. After complete emptying of the stomach by aspiration, $500 \mathrm{ml}$ of a liquid meal, containing $8 \%$ peptone (wt/vol) (Bacto Peptone, Difco Laboratories, Inc., Detroit, MI), was instilled intragastrically and acid secretion was measured during $1 \mathrm{~h}$ by automated intragastric titration (16). During the test the volume of the intragastric contents was measured at $5,15,30,45$, and $60 \mathrm{~min}$, using the dye-dilution technique (17). Phenol red was used as marker. Its concentration was measured spectrophotometrically at $\mathrm{pH} 11$, at a wavelength of $560 \mathrm{~nm}$ (Model DU, Beckman Instruments, Inc., Fullerton, 
CA). The duodenal acid load during meals at low $\mathrm{pH}$ was calculated according to Gross et al. (18). Titratable acid of the gastric contents was measured by titration to $\mathrm{pH} 7$.

Before and during tests blood samples were taken through a needle in the antecubital vein for measurement of plasma gastrin and secretin concentrations. Samples were collected in standard EDTA-containing tubes ( $10.5 \mathrm{mg} /$ tube) to which $200 \mu \mathrm{l}$ Trasylol (aprotinin), 10,000 KIU/ $\mathrm{ml}$ (Bayer AG, Bayerwerk, FRG) per $5 \mathrm{ml}$ blood was added. Samples were refrigerated immediately after collection, centrifuged within 30 min, and the plasma was stored at $-20^{\circ} \mathrm{C}$ until radioimmunoassays were performed.

For secretin infusion pure natural porcine secretin (manufactured by Kabi Vitrum AB, Stockholm, Sweden) dissolved in $0.15 \mathrm{M} \mathrm{NaCl}$, containing $0.25 \%$ human serum albumin ( $w t / v o l$ ), was used. The infusion was administered through a needle in the other arm. A small portion of each infusion solution was stored at $-20^{\circ} \mathrm{C}$ for measurement of the secretin concentration. The biologic activity of the secretin was tested by infusing increasing doses intravenously in a dog with a chronic pancreatic fistula after an overnight fast, and measuring pancreatic secretion in respect to volume and bicarbonate contents. Gastrin plasma concentrations were measured with a specific radioimmunoassay as previously described (19), using antibody 1611 .

Secretin plasma levels were measured with a newly developed radioimmunoassay.

Antibody. Secretin antibodies were raised in rabbits, using synthetic secretin (E. R. Squibb \& Sons, Princeton, NJ) as antigen. The secretin was conjugated to bovine serum albumin with carbodiimide as described earlier (19). The conjugation product was emulsified with complete Freund's adjuvant for the initial immunization, and with incomplete Freund's adjuvant for subsequent booster immunizations. Booster immunizations were given at 4-8-wk intervals after the previous immunization. Blood was obtained $7 \mathrm{~d}$ after an immunization. The antiserum used in this assay, 7842, was obtained after the fourth immunization.

Cross-reactivity of the antiserum was tested for glucagon, gastric inhibitory peptide, and vasoactive intestinal peptide and further for bombesin, cholecystokinin octapeptide, gastrin, insulin, motilin, neurotensin, pancreatic polypeptide, and somatostatin at concentrations up to at least $10 \mathrm{pmol} / \mathrm{ml}$.

The sensitivity was tested by determining the $\mathrm{ID}_{50},{ }^{1}$ defined as the concentration of antigen required to reduce the binding of labeled antigen by $50 \%$, and by determining the detection limit, defined as the smallest concentration of added antigen, which produces a significant inhibition of binding $(P<0.05$ by $t$ test), when samples are tested in four replications.

Labeled antigen. Secretin was labeled by the chloramine-T method. Synthetic secretin was purchased from Research Plus, $\mathrm{Na}^{125} \mathrm{I}(100 \mathrm{mCi} /$ $\mathrm{ml}$ ) from Amersham Corp. I; chloramine-T from Eastman Kodak Co., Rochester, NY; sodium metabisulphite from J. T. Baker Chemical Co., Phillipsburg, NJ; Sephadex G-10 and SP-Sephadex C-25 from Pharmacia Fine Chemicals, Piscataway, NJ. Secretin, chloramine-T, and sodium metabisulphite were all dissolved in $0.25 \mathrm{M}$ sodium phosphate buffer at $\mathrm{pH} 7.4$.

Secretin, 10-20 $\mu \mathrm{g}$, was dissolved in $50 \mu \mathrm{l}$ buffer, to which $10 \mu \mathrm{l}$ $\mathrm{Na}^{125} \mathrm{I}$ and $20 \mu \mathrm{g}$ chloramine-T in $10 \mu \mathrm{l}$ buffer, were added. After a reaction time of $60 \mathrm{~s} 100 \mu \mathrm{g}$ sodium metabisulphite in $20 \mu \mathrm{l}$ buffer was added.

For a first purification the sample was applied to a Sephadex G-10 column, $20 \times 1 \mathrm{~cm}$, eluted with $0.05 \mathrm{M}$ sodium acetate buffer $\mathrm{pH} 5.0$,

1. Abbreviation used in this paper: $\mathrm{ID}_{50}$, concentration of antigen required to reduce the binding of labeled antigen by $50 \%$. containing $0.425 \%$ sodium chloride (wt/vol) and $2 \%$ Plasmanate (human plasma protein fraction, Cutter Laboratories, Inc., Emeryville, CA). The flow rate was $1 \mathrm{ml} / \mathrm{min}$, and 2-ml fractions were collected. From the first peak the fractions with the highest radioactivity were pooled, and, for further purification, applied to a SP-Sephadex C-25 column, 20 $\times 1 \mathrm{~cm}$, eluted with the same buffer as the first column, but with a concentration gradient from 0.05 to $0.1 \mathrm{M}$ in $0.85 \% \mathrm{NaCl}$ over $12 \mathrm{~h}$, at a flow rate of $0.2 \mathrm{ml} / \mathrm{min}$. Fractions of $2 \mathrm{ml}$ were collected. From the second high peak the fractions with the highest radioactivity, containing the purified label, were pooled and after addition of $0.5 \%$ Trasylol, $10,000 \mathrm{KIU} / \mathrm{ml}$, (vol/vol), divided in $250-\mu l$ portions, which were stored at $-20^{\circ} \mathrm{C}$ until use. Each portion was used for only one assay. Fractions preceding and following the labeled antigen containing peak were assayed to identify unlabeled secretin.

The specific activity of the label was determined by comparing the displacement of a known amount of labeled antigen by doubling amounts of the same label and known amounts of standard secretin.

The immunoreactivity was determined by comparing serial dilution curves of the labeled secretin and standard secretin, and by determining the binding of label to an excess amount of antibody (titer 1:5,000). To each assay tube $2,000 \mathrm{cpm}$ of label in $200 \mu \mathrm{l}$ were added. Counting time was $1 \mathrm{~min}$.

Standard secretin. Squibb synthetic secretin was used as standard. The dry powder was dissolved in the assay buffer to a concentration of $1 \mathrm{nmol} / \mathrm{ml}$. $250-\mu \mathrm{l}$ portions of this solution were stored at $-20^{\circ} \mathrm{C}$, each portion to be used for only one assay.

Assay conditions. The incubation volume was $1 \mathrm{ml}$. The assay buffer was $0.05 \mathrm{M}$ ammonium acetate (J. T. Baker Chemical Co.) at pH 5.5, containing $2 \%$ Plasmanate and $0.5 \%$ Trasylol. In preliminary experiments we found that at higher $\mathrm{pH}(6.5,7.4)$ the binding in absence of antibody exceeded $10 \%$, which we found unacceptable.

The standards and unknown samples were preincubated at $4^{\circ} \mathrm{C}$ with the antibody for $48 \mathrm{~h}$, after which label was added. After another $24 \mathrm{~h}$ at $4^{\circ} \mathrm{C}$, bound and unbound fractions were separated, using charcoal. For the separation $400 \mu \mathrm{l}$ of a suspension of activated charcoal (Mallinckrodt Inc., St. Louis, MO), $50 \mathrm{mg} /$ liter, and dextran (Pharmacia Fine Chemicals), $5 \mathrm{mg} /$ liter, in $0.05 \mathrm{M}$ ammonium acetate at $\mathrm{pH} 5.5$, with $10 \%$ newborn calf serum (vol/vol) (MA Bioproducts, Walkersville, $\mathrm{MD}$ ), was added to each tube. After centrifugation the bound and unbound fractions were separated. In preliminary experiments it was found that by this incubation method the $\mathrm{ID}_{50}$ decreased $70 \%$ compared with simultaneous incubation of antibody and label for $24 \mathrm{~h}$.

Data fitting. For the standard curve, antigen concentrations of 1 $1,000 \mathrm{fmol} / \mathrm{ml}$ were used. A computer fit the four-parameter logistic curve to the bound counts with nonlinear regression. The computer was also used to obtain unknown values from the standard curve (20).

Reproducibility of the assay. This was determined by calculating the coefficients of variation within the assay and between assays.

Preparation of plasma samples. Since physiologic plasma levels of secretin are low and plasma interference is often relatively high, extraction and concentration of plasma is necessary before assaying. For this purpose we used $\mathrm{C}_{18}$ cartridges (SEP-PAK, Waters Associates, Millipore Corp., Milford, MA), small, densely packed $\mathrm{C}_{18}$ columns. After preparation of the cartridge with $10 \mathrm{ml}$ acetonitrile (J. T. Baker Chemical Co) and 10 $\mathrm{ml} 0.05 \mathrm{M}$ ammonium acetate at $\mathrm{pH} 5.5$, the plasma sample was applied. The column was then washed with the same buffer and it was then eluted with $50 \%$ acetonitrile $/ 50 \%$ ammonium acetate. After discarding the first $0.5 \mathrm{ml}, 1.1 \mathrm{ml}$ was collected in a tube containing $0.01 \mathrm{ml}$ Plasmanate and $0.005 \mathrm{ml}$ Trasylol. After evaporation of the acetonitrile $0.6 \mathrm{ml}$ ammonium acetate buffer was left; $450 \mu \mathrm{l}$ of the 600 was added 
to the assay tube. From each plasma sample $2 \times 5 \mathrm{ml}$ was extracted and assayed as duplicates. Recovery of secretin from this procedure was tested by adding doubling doses of standard secretin to $5 \mathrm{ml}$ of charcoalstripped hormone-free plasma, at concentrations of $3.125-25 \mathrm{fmol} / \mathrm{ml}$ plasma and extracting and assaying the samples as mentioned before. To determine remaining interference after extraction, from each subject studied, $10 \mathrm{ml}$ plasma was treated with charcoal and $2 \times 5 \mathrm{ml}$ was extracted and assayed with the other samples. The same was done with the plasma used for recovery tests. Concentrations of unknowns were calculated from the assay results by correction for the recovery, the volume extracted $(5 \mathrm{ml})$, the final fraction of the sample used in the assay (450/600), and for remaining interference after extraction.

Studies performed. Four studies were performed on separate days, the first three in random order. In these three the liquid meals were given at $\mathrm{pH} 2.0,2.5$, and 5.5, respectively, and intragastric titration was performed at the same $\mathrm{pH}$ as the meals. A basal blood sample was taken before the meal while aspirating gastric contents, and during the test samples were taken at 15 -min intervals. On the same day as the test with the meal at pH 5.5, $2 \mathrm{~h}$ after finishing that test, secretin was infused in increasing doses, respectively, $2.5,8.0$, and $25.0 \mathrm{pmol} \cdot \mathrm{kg}^{-1} \cdot \mathrm{h}^{-1}$. Each dose was infused during $30 \mathrm{~min}$. At the end of each period a blood sample was taken. During the infusion gastric contents were aspirated continuously.

In the fourth study, a liquid meal at pH 5.5 was again given, now along with intravenous infusion of secretin at a dose designed to match plasma levels found during the meals at low $\mathrm{pH}$. The required dose was estimated on an individual basis by comparison of the plasma secretin found during the meals at low $\mathrm{pH}$ and the levels during the infusion of increasing doses of secretin. The secretin infusion was started at the same moment as the instillation of the meal. Blood was collected at 15min intervals for gastrin and at 30 and $60 \mathrm{~min}$ for secretin.

In four subjects, two additional studies were performed. In both, again a meal at pH 5.5 was given. In the first, secretin was infused only during the meal at a dose five- to sixfold higher than the dose given in the former study. In the second, secretin was infused at the same dose as in the first, but the infusion was started $1 \mathrm{~h}$ before the meal and continued throughout the test. Gastric emptying was not studied in these two tests. Blood samples were taken at 15-min intervals for gastrin and at 30-min intervals for secretin.

Data analysis. For each test in each subject the integrated responses for gastrin and secretin were calculated. For gastrin the integrated response was calculated using the natural logs of the responses. The integrated mean was obtained by dividing this value by the time $(60 \mathrm{~min})$. Twoway analysis of variance (subject by condition) was performed on these integrated means. Gastrin values given are the mean logs, transformed back to the raw scale. For acid, total secretion during the test hour was used in the analysis of variance without considering basal acid secretion. For the gastric emptying the $t^{1 / 2}$ was calculated separately for each test of each subject using a nonlinear fit to the single exponential (21). Twoway analysis of variance was calculated using these estimates of $t \frac{1}{2}$.

\section{Results}

\section{Secretin radioimmunoassay}

Antibody. The final titer of the antibody used in the assay was $1: 400,000$. Glucagon at a concentration of $1 \mathrm{nmol} / \mathrm{ml}$ produced a $10 \%$ inhibition of binding of the label to the antibody. No other cross-reactivity was detected. (Fig. 1).

Labeled antigen. The specific activity of the label was 2.5

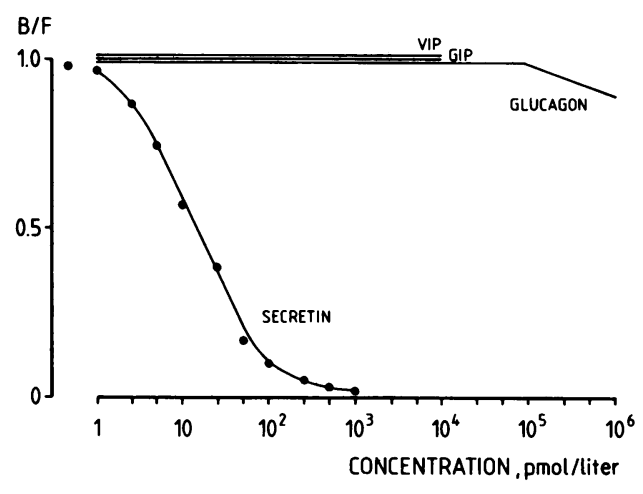

Figure 1. Representative standard curve of the radioimmunoassay for secretin; the concentration of standard secretin (pmol/liter) $(x=$ axis) plotted against ratio of bound-to-free labeled secretin $(y$ $=$ axis). Dilution curves for glucagon, gastric inhibitory peptide (GIP), and vasoactive intestinal peptide (VIP) in the same assay system.

$\mu \mathrm{Ci} / \mathrm{nmol}$. The dilution curve of the label was parallel to the standard curve. In the presence of excess antibody $85 \%$ of the label was bound. Unlabeled secretin eluted on the SP-Sephadex $\mathrm{C}-25$ column in the fractions preceding those containing the labeled secretin.

Assay. The detection limit of antigen added to assay buffer was $2.6 \pm 1.4 \mathrm{fmol} / \mathrm{ml}$, the $\mathrm{ID}_{50}$ was $12.9 \pm 2.0 \mathrm{fmol} / \mathrm{ml}$ (mean $\pm \mathrm{SD}$ ). Fig. 1 shows a representative standard curve. The addition of Trasylol to the assay buffer decreased the $\mathrm{ID}_{50}$ by $20 \%$. Binding of the label in the absence of antibody was $6.7 \pm 1.8 \%$. The ratio of bound over free label in the absence of unlabeled antigen was $1.06 \pm 0.2$.

Reproducibility. The coefficient of variation within assays was $7 \%$ at $16 \mathrm{fmol} / \mathrm{ml}, 15 \%$ at 10 , and $13 \%$ at $5 \mathrm{fmol} / \mathrm{ml}$, and between assays $16 \%$ at 16 and $21 \%$ at $5 \mathrm{fmol} / \mathrm{ml}$.

Preparation of plasma samples. The recovery from the extraction procedure was $66 \pm 7 \%$. The recovery was slightly higher at higher concentrations. However, the ranges were the same, and the differences were not significant (Table I). Interference after extraction of charcoal treated plasma was $1.1 \pm 0.9 \mathrm{fmol} /$ $5 \mathrm{ml}$ plasma.

\section{Human studies}

Plasma secretin. During the meals at low pH a rise of plasma secretin concentrations was seen during the first 30 min (peak

Table I. Recovery of Standard Secretin, Added to Hormone-free Plasma, after Extraction and Concentration from $C_{18}$ Cartridges

\begin{tabular}{lllll}
\hline $\begin{array}{l}\text { Concentration } \\
\text { Secretin, PM }\end{array}$ & $\begin{array}{l}3.125 \\
n=7\end{array}$ & $\begin{array}{l}6.25 \\
n=13\end{array}$ & $\begin{array}{l}12.5 \\
n=10\end{array}$ & $\begin{array}{l}25.0 \\
n=4\end{array}$ \\
\hline $\begin{array}{l}\text { Recovery, \% } \\
\text { (Mean } \pm \text { SD) }\end{array}$ & $62 \pm 13$ & $64 \pm 10$ & $67 \pm 10$ & $72 \pm 10$ \\
\hline
\end{tabular}


concentration $\mathrm{pH} 2.0,5.7 \mathrm{fmol} / \mathrm{ml}$; $\mathrm{pH} 2.5,5.4 \mathrm{fmol} / \mathrm{ml}$ ) after which the concentrations fell to almost basal at $60 \mathrm{~min}$. During the meal at $\mathrm{pH} 5.5$ plasma secretin did not increase. When secretin was infused in increasing doses there was a good correlation $(r=0.93)$ between the increases of plasma secretin and the infusion rate of secretin, as calculated from the measured secretin concentrations (Fig. 2). The clearance rate calculated from these data (infusion rate/plasma concentration) was $15.2 \pm 6.6 \mathrm{ml} \cdot \mathrm{kg}^{-1} \cdot \mathrm{min}^{-1}($ mean $\pm \mathrm{SD})$. The mean dose of secretin needed to match the plasma concentrations found during the meals at low $\mathrm{pH}$ was $5.6 \mathrm{pmol} \cdot \mathrm{kg}^{-1} \cdot \mathrm{h}^{-1}$ (range $2.3-9.5$ ). The integrated means of plasma secretin concentrations during the meals of low $\mathrm{pH}$ and the meal of $\mathrm{pH} 5.5$ with secretin infusion did not differ. The results are summarized in Table II and Fig. $3 \mathrm{~A}$.

Gastrin. Compared with the meal of pH 5.5 there was a significant inhibition of gastrin release during the meals of low $\mathrm{pH}$. The infusion of secretin during the meal of $\mathrm{pH} 5.5$ did not influence gastrin release (Fig. $3 B$ and Table II).

Acid secretion. Acid secretion was significantly lower during the meals of low $\mathrm{pH}$, compared with the meal of $\mathrm{pH}$ 5.5. Acid

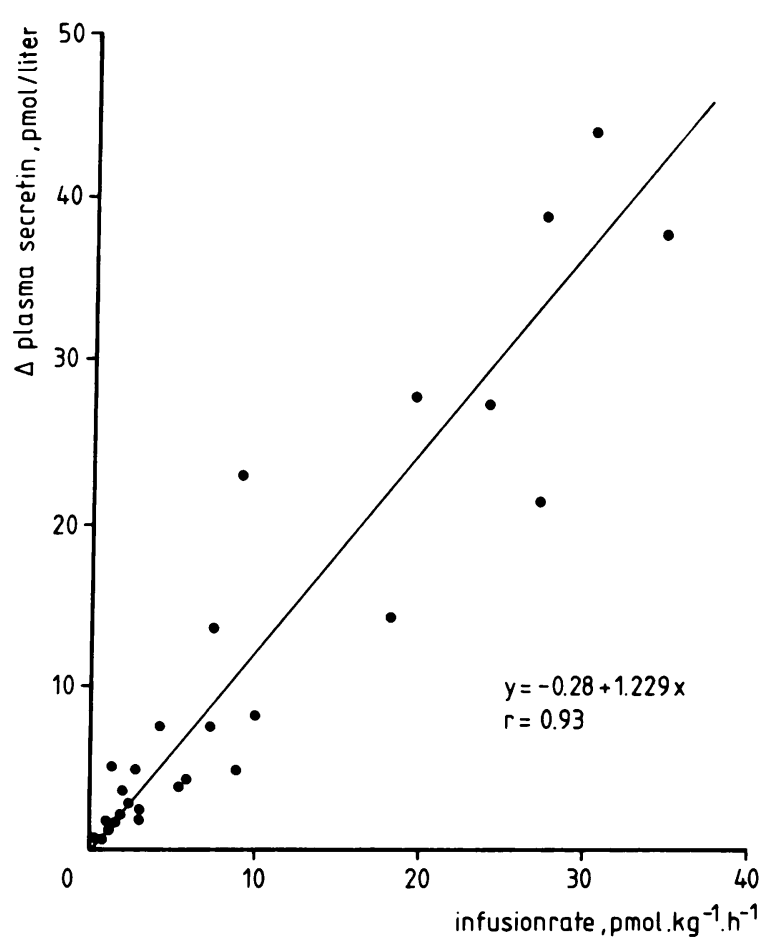

Figure 2. Correlation in nine healthy male subjects between infusion rate $\left(\mathrm{pmol} \mathrm{kg}^{-1} \mathrm{~h}^{-1}\right)$ of pure porcine secretin, as determined from the radioimmunoassay measured concentrations of the hormone in the infusion solutions and the increase from basal of the plasma secretin concentrations (pM), as measured by radioimmunoassay, using $C_{18}$ cartridges for the extraction and concentration of secretin from plasma. $P$ $<0.001$.

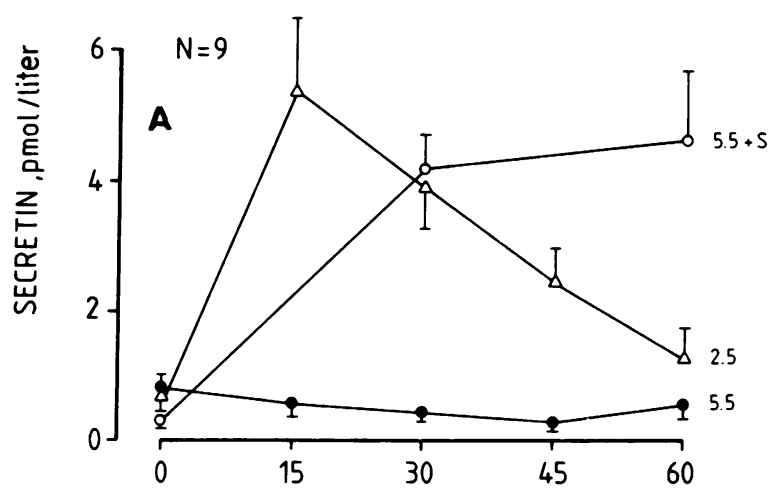

TIME (MINUTES) AFTER INSTILLATION MEAL

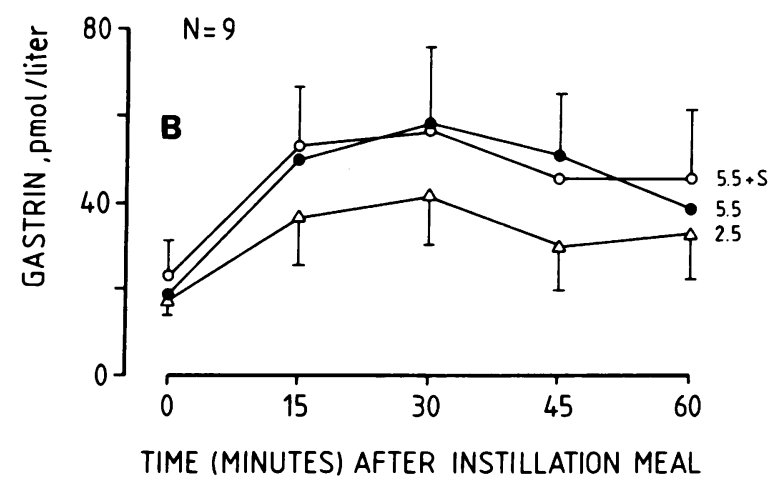

Figure 3. Mean $( \pm \mathrm{SE})$ basal and protein-stimulated $(500 \mathrm{ml}$ $8 \%$ peptone solution) plasma secretin and plasma gastrin concentrations (pM) during intragastric titration at $\mathrm{pH} 2.5$ and $\mathrm{pH} 5.5$ and at $\mathrm{pH} 5.5$ with concomitant secretin infusion in a dose designed to match the plasma concentration found during the test at $\mathrm{pH} 2.5$ ( $\mathrm{pH} 5.5$ plus secretin), in nine healthy male subjects. Plasma secretin and gastrin concentrations were determined by radioimmunoassay.

secretion could be evaluated in only six subjects, because duodenogastric reflux of bicarbonate occurred in one subject during secretin infusions at pH 5.5 and in two subjects during secretin infusion at pH 2.5 and caused sudden increases in intragastric $\mathrm{pH}$. No difference was seen between acid secretion during the meals at pH 5.5 with or without concomitant secretin infusion (Table II).

Duodenal acid load. The maximal duodenal acid load during the meals of low pH occurred during the first $15 \mathrm{~min}$, and subsequently decreased (Table III).

Gastric emptying. Gastric emptying rate was significantly slower at low intragastric $\mathrm{pH}$ than during intragastric $\mathrm{pH}$ of 5.5. The $t^{1 / 2}$ during the meal of pH 5.5 with concomitant secretin infusion was longer than during the meal without secretin, but this difference was not quite significant $(P=0.053)$ (Table IV).

High dose secretin infusion. Similar mean secretin plasma 
Table II. Mean Acid Secretion and Mean Plasma Gastrin and Secretin Concentrations (Integrated Response/60 min) during $1 \mathrm{~h}$ Intragastric Titration after Gastric Instillation of $500 \mathrm{ml} 8 \%$ Peptone Solution

\begin{tabular}{llll}
\hline pH meal & $\begin{array}{l}\text { Acid secretion } \\
n=6\end{array}$ & $\begin{array}{l}\text { Mean gastrin } \\
n=9\end{array}$ & $\begin{array}{l}\text { Mean secretin } \\
n=9\end{array}$ \\
\hline & $m m o l / h$ & $p M$ & $p M$ \\
5.5 & 15.7 & 33 & $0.6 \ddagger$ \\
5.5 plus secretin & 14.9 & 33 & $3.4^{*}$ \\
2.5 & $10.6^{*} \ddagger$ & $20^{*} \ddagger$ & $3.2^{*}$ \\
2.0 & $7.9^{*} \ddagger$ & $18^{*} \ddagger$ & $3.9^{*}$ \\
\hline
\end{tabular}

S, concomitant secretin infusion.

* Significantly different from 5.5

‡ Significantly different from 5.5 plus secretin.

levels during the plateau phase were found during the 1-h and the 2-h tests (33 and $36 \mathrm{pM}$, respectively, mean dose 32 $\left.\mathrm{pmol} \cdot \mathrm{kg}^{-1} \cdot \mathrm{h}^{-1}\right)$. Neither during the $1-\mathrm{h}$ infusion nor during the 2-h infusion was the mean plasma gastrin different from that during the meal without secretin ( 36 and 34 vs. 45 pM). Acid secretion could not be measured during these tests because of duodenogastric reflux, which was apparent since the intragastric pH fluctuated above 5.5 during most of the tests.

Biologic activity of secretin. During the infusion of 2.5, 8.0, and $25 \mathrm{pmol} \cdot \mathrm{kg}^{-1} \cdot \mathrm{h}^{-1}$ secretin in $0.15 \mathrm{M} \mathrm{NaCl}$ with $1 \%$ bovine serum albumin into the test dog, the volume and bicarbonate concentration of the pancreatic secretion increased progressively from basal values of $2.2 \mathrm{ml} / 15 \mathrm{~min}$ and $61 \mathrm{mM}$ to maximal values of $8.3 \mathrm{ml} / 15 \mathrm{~min}$ and $113 \mathrm{mM}$.

\section{Discussion}

Secretin radioimmunoassay. The radioimmunoassay for secretin has characteristics similar to those of other assays described in recent years $(1,22-25)$. The ID $_{50}$ of $12.9 \mathrm{fmol} / \mathrm{ml}$ compares well with other assays; however, the detection limit of $2.6 \mathrm{fmol} /$ $\mathrm{ml}$ is slightly higher than that reported in several other assays. Because of the low physiologic plasma levels it was therefore necessary to develop a method for extraction and concentration of plasma by which larger volumes per plasma sample could be processed than with the alcohol extraction method, in order to be able to measure those low levels reliably. The method

Table III. Duodenal Acid Load (Millimoles) (mean \pm SEM) during 1 h Intragastric Titration after Gastric Instillation of 500 ml 8\% Peptone Solution at $\mathrm{pH} 2.0$ and $2.5(n=6)$

\begin{tabular}{lrrrr}
\hline pH meal & $0-15 \mathrm{~min}$ & $15-30 \mathrm{~min}$ & $30-45 \mathrm{~min}$ & $45-60 \mathrm{~min}$ \\
\hline 2.0 & $19.6 \pm 4.7$ & $12.3 \pm 3.7$ & $11.3 \pm 3.3$ & $5.9 \pm 1.2$ \\
2.5 & $19.1 \pm 2.8$ & $7.1 \pm 2.3$ & $11.0 \pm 2.0$ & $7.1 \pm 2.0$ \\
\hline
\end{tabular}

Table IV. Rate of Gastric Emptying during 1 h Intragastric Titration after Gastric Instillation of $500 \mathrm{ml} 8 \%$ Peptone Solution $(n=8)$

\begin{tabular}{ll}
\hline $\mathrm{pH}$ meal & $\mathrm{t} / 2$, mean $\pm \mathrm{SEM}$ \\
\hline & $\min$ \\
5.5 & $29 \pm 3$ \\
5.5 plus $\mathrm{S}$ & $47 \pm 9 \ddagger$ \\
2.5 & $74 \pm 12^{*}$ \\
2.0 & $79 \pm 10^{*}$ \\
\hline
\end{tabular}

$t 1 / 2=$ calculated time, at which the stomach is half empty; $\mathbf{S}$, concomitant secretin infusion.

* Significantly different from 5.5 .

$¥$ Not significantly different from $5.5, P=0.053$.

described in this study offers the possibility to measure plasma concentrations as low as $1.3 \mathrm{fmol} / \mathrm{ml}$. The recovery of the secretin from the SEP-PAK, $66 \%$, is about the same as found with the alcohol extraction method $(23,25)$ and similar to that reported earlier for similar extraction (26). Remaining interference after extraction of plasma has also been reported by others, and is quantitatively not different from other reported data (25). Although most investigators add Trasylol to the assay buffer, only one reported its influence on the assay, saying that it did not interfere with the results (23). We found that the addition of $0.5 \%$ Trasylol $10,000 \mathrm{KIU} / \mathrm{ml}$ consistently improved the $\mathrm{ID}_{50}$ of the assay by $20 \%$. An explanation may be that Plasmanate used as protein in our buffer may contain enzymes and the use of bovine serum albumin might make the addition of Trasylol unnecessary. The finding of a close correlation between the secretin infusion rates and the increases of plasma increases is a firm validation of our assay and the extraction procedure. The metabolic clearance rate found is similar to what Schaffalitsky de Muckadell et al. found (4).

Human studies. Based on the studies $(7,8)$ that showed that exogenous secretin can inhibit acid secretion and gastrin release in man, it has been postulated that secretin may play a physiologic role in the inhibition of acid secretion and gastrin release. However, in these studies unphysiologically high doses of secretin were infused. Since the development of reliable radioimmunoassays for secretin, it is known that basal plasma levels of secretin are very low and that after meals only small absolute increases occur. Recent studies $(11,12)$ in dogs indicate that at these low levels secretin can inhibit acid secretion and gastrin release, and that in dogs secretin may play a physiologic role in the inhibition of acid secretion. In this study we found a strong inhibition of acid secretion and gastrin release by a low intragastric $\mathrm{pH}$. The data on gastric acid secretion at $\mathrm{pH}$ 2.0 have to be considered with caution, since intragastric titration at that $\mathrm{pH}$ may underestimate the amount of acid produced by up to $\sim 25 \%$ depending on the concentration of the secreted $\mathrm{HCl}$ (27). However, also at pH 2.5 a significant inhibition oc- 
curred. In contrast, exogenous secretin producing plasma levels similar to those found during meals of low $\mathrm{pH}$ did not inhibit gastrin release and acid secretion during a meal of $\mathrm{pH} 5.5$. Although the peak levels of secretin during the meals of low $\mathrm{pH}$ were slightly higher than the plateau levels during the secretin infusion $(5.5$ vs. $4.6 \mathrm{fmol} / \mathrm{ml})$, it is unlikely that this explains the lack of inhibitory effect by secretin, because the mean levels were similar in these studies. Several facts may contribute to the differences found between humans and dogs. Postprandial plasma levels of secretin, as measured by the same radioimmunoassay, are higher in dogs than in men $(5,24)$. Further, dogs seem to be more sensitive to the acid-inhibiting effect of secretin than men (7). A possible explanation for these differences could be a structural difference between human and porcine and/or canine secretin, that could produce falsely low radioimmunoassay values in men and/or a lower biologic activity.

The doses of secretin infused during the meals of $\mathrm{pH} 5.5$ produce a marked increase of pancreatic secretion, and are therefore thought to produce physiologic plasma concentrations. It might thus be expected that the secretin given in this study could inhibit the gastrin release if it plays a physiologic role in this inhibition. Our results are in agreement with an earlier report in which it was shown that secretin was not responsible for the inhibition of pentagastrin-stimulated acid secretion by intraduodenal acidification (28-30), nor was it apparently the cause of inhibition of histamine-stimulated secretion (31).

Apparently factors other than secretin are the mediators of the acid-induced inhibition of gastrin release, which we found to be responsible for inhibition of acid secretion by low intragastric $\mathrm{pH}$. Whether the mechanism of this inhibition is through intragastric pathways or whether mechanisms through receptors in the duodenal or intestinal wall are involved is an unsolved question. The inhibition by intraduodenal acidification is independent of gastrin (28), and thus does not seem to play a great role in the inhibition by low intragastric $\mathrm{pH}$, which is primarily an inhibition of gastrin release.

Further studies are necessary to determine the mechanisms involved in the acid-induced inhibition of acid secretion. Hormonal, paracrine, and neural mechanisms and substances such as somatostatin, vasoactive intestinal peptide, and prostaglandins may be involved.

The finding that exogenous secretin at doses five- to sixfold higher than those found during the meals at low $\mathrm{pH}$ does not significantly inhibit the gastrin release is not in disagreement with other studies, although a real difference might have become apparent if larger numbers of subjects had been studied. Dalton et al. (8) found that secretin in doses up to $0.5 \mathrm{CU} \cdot \mathrm{kg} \cdot{ }^{-1} \cdot \mathrm{h}^{-1}$ equivalent to $41 \mathrm{pmol} \cdot \mathrm{kg}^{-1} \cdot \mathrm{h}^{-1}$ did not inhibit gastrin release in response to a steak meal, but these authors did not add protein to the infusion solution so it may well be that they gave lower doses than they had intended. Londong et al. (9) found that peptone-stimulated gastrin release was inhibited by 0.5 $\mathrm{CU} \cdot \mathrm{kg}^{-1} \cdot \mathrm{h}^{-1}$ secretin, but this effect first became apparent during the second half hour of the first hour after the start of the study, and the integrated mean over the first hour was probably not different whether they gave secretin or not. Whether these high levels of secretin inhibit gastrin release and/or acid secretion is probably not important for an understanding of physiologic mechanisms, since these levels are never seen under pure physiologic conditions.

A low intragastric pH clearly inhibits gastric emptying. Although we did not find a significant inhibition by secretin, secretin may still play a role in the inhibition of gastric emptying as the findings of Valenzuela and Defilippi (13) suggest. We studied only eight subjects and the borderline significance $(P$ $=0.053$ ) may have been due to this small number.

We conclude that secretin does not play a role in the acidinduced inhibition of peptone stimulated acid secretion and is unlikely to have a physiologic role in the inhibition of acid secretion in man. The role that secretin may play in the acidinduced inhibition of gastric emptying seems to be a minor one.

\section{Acknowledgments}

Dr. Janet Elashoff and Dr. Terry Reedy are gratefully acknowledged for their help in statistical analysis.

This work was supported by National Institutes of Health grants AM 17294 and AM 17328. Dr. J. H. Kleibeuker was a recipient of a Fullbright grant (home institution, Department of Medicine, University Hospital, Groningen, The Netherlands). Dr. V. E. Eysselein was supported by the Deutsche Forschungs Gemeinschaft.

\section{References}

1. Greenberg, G. R., R. F. McCloy, J. H. Baron, M. G. Bryant, and S. R. Bloom. 1982. Gastric acid regulates the release of plasma secretin in man. Eur. J. Clin. Invest. 12:361-372.

2. Pelletier, M. J., J. A. P. Chayvialle, and Y. Minaure. 1978. Uneven and transient secretin release after a liquid test meal. Gastroenterology. 75:1124-1132.

3. Fahrenkrug, J., O. B. Schaffalitsky de Muckadell, and S. J. Rune. 1978. $\mathrm{pH}$ threshold for release of secretin in normal subjects and in patients with duodenal ulcer and patients with chronic pancreatitis. Scand. J. Gastroenterol. 13:177-186.

4. Schaffalitsky de Muckadell, O. B., J. Fahrenkrug, S. W. Boolsen, and $\mathrm{H}$. Worming. 1978. Pancreatic response and plasma secretin concentration during infusion of low dose secretin in man. Scand. J. Gastroenterol. 13:305-311.

5. Chey, W. Y., M. S. Kim, K. Y. Lee, and T. M. Chang. 1979. Effect of rabbit antisecretin serum on postprandial pancreatic secretion in dogs. Gastroenterology. 77:1266-1275.

6. Waldum, H. L., N. Walde, and P. G. Burhol. 1981. The effect of secretin on gastric $\mathrm{H}^{+}$and pepsin secretion and on urinary electrolyte elevation in man. Scand. J. Gastroenterol. 16:999-1004.

7. Brooks, A. M., and M. I. Grossman. 1970. Effect of secretin and cholecystokinin on pentagastrin-stimulated gastric secretion in man. Gastroenterology. 59(1):114-119.

8. Dalton, M. D., A. M. Eisenstein, J. H. Walsh, and J. S. Fordtran. 1976. Effect of secretin on gastric function in normal subjects and in patients with duodenal ulcer. Gastroenterology. 71:24-29.

9. Londong, W., V. Londong, L. E. Hanssen, and A. Schwanner. 1981. Gastric effects and side effects of synthetic secretin in man. Regul. Pept. 2:231-244. 
10. Jansen, J. B. M. J., and C. B. M. W. Lamers. 1981. Calcitonin and secretin inhibit bombesin-stimulated serum gastrin and gastric acid secretion in man. Regul. Pept. 1:415-421.

11. Chey, W. Y., M. S. Kim, K. Y. Lee, and T. M. Chang. 1981. Secretin is an enterogastrone in the dog. Am. J. Physiol. 240:G239G244.

12. Kim, Y. M., K. Y. Lee, and W. Y. Chey. 1981. Role of secretin on postprandial gastrin release in the dog: A further study. Surgery (St. Louis). 90:504-508.

13. Valenzuela, J. E., and C. Defilippi. 1981. Inhibition of gastric emptying in humans by secretin, the octapeptide of cholecystokinin and intraduodenal fat. Gastroenterology. 81:898-902.

14. Eysselein, V. E., J. H. Kleibeuker, V. Maxwell, T. Reedy, and J. H. Walsh. 1983. Inhibition of gastric acid secretion at low intragastric pH in man: relation to plasma gastrin. Gastroenterology. 84:1147a. (Abstr.)

15. Hassan, M. A., and M. Hobsley. 1970. Positioning of subject and of nasogastric tube during a gastric secretion study. Br. Med. J. 1:458-460.

16. Lam, S. K., J. I. Isenberg, M. I. Grossman, W. H. Lane, and J. H. Walsh. 1980. Gastric acid secretion is abnormally sensitive to endogenous gastrin released after peptone test meals in duodenal ulcer patients. J. Clin. Invest. 65:555-562.

17. George, J. D. 1968. New clinical method for measuring the rate of gastric emptying: the double-sampling test meal. Gut. 9:237-242.

18. Gross, R. A., J. I. Isenberg, D. Hogan, and I. M. Samloff. 1978. Effect of fat on meal-stimulated duodenal acid load, duodenal pepsin load, and serum gastrin in duodenal ulcer and normal subjects. Gastroenterology. 75:357-362.

19. Rosenquist, G. L., and J. H. Walsh. 1980. Radioimmunoassay of gastrin. In Gastrointestinal Hormones. G. B. Jerzy Glass, editor. Raven Press, New York, 769-795.
20. Rodbard, D., et al. 1975. Radioimmunoassay Data Processing: Listings and Documentation, Third ed. The Logistic Method and Quality Control (PB246 or 224). U. S. Department of Commerce, National Technical Information Service, Springfield, VA. Vol. 2.

21. Elashoff, J. D., T. R. Reedy, and J. H. Meyer. 1982. Analysis of gastric emptying data. Gastroenterology. 83:1306-1312.

22. Burhol, P. G., and H. L. Waldun. 1975. Radioimmunoassay of secretin in acidified plasma. Acta Hepatogastroenterol. 25:474-481.

23. Hanssen, L. E., and P. Torjesen. 1977. Radioimmunoassay of secretin in human plasma. Scand. J. Gastroenterol. 12:481-488.

24. Rominger, J. M., W. Y. Chey, and T. M. Chang. 1981. Plasma secretin concentrations and gastric $\mathrm{pH}$ in healthy subjects and patients with digestive diseases. Dig. Dis. Sci. 26:591-597.

25. Schaffalitsky de Muckadell, O. B., and J. Fahrenkrug. 1977. Radioimmunoassay of secretin in plasma. Scand. J. Clin. Lab. Invest. 37:155-162.

26. Yang, R.-K., Li, H.-R., Eng, J., Greenstein, R., Straus, E., and Yalow, R. S. 1983. Secretin responses to feeding and acid load. J. Lab. Clin. Med. 102:17-23.

27. Spenney, J. G. 1979. Physical chemical and technical limitations of intragastric titration. Gastroenterology. 76:1025-1036.

28. Ward, A. S., and S. R. Bloom. 1974. The role of secretin in the inhibition of gastric secretion by intraduodenal acid. Gut. 15:889-897.

29. Wormsley, K. G. 1970. Response to duodenal acidification in man. II. Effects on the gastric secretory response to pentagastrin. Scand. J. Gastroenterol. 5:207-215.

30. Berstad, A., and H. Petersen. 1970. Dose-response relationship of the effect of secretin on acid and pepsin secretion in man. Scand. J. Gastroenterol. 5:647-654.

31. Johnston, D., and H. L. Duthie. 1966. Inhibition of histaminestimulated gastric secretion by acid in the duodenum in man. Gut. 7:58-68. 